\title{
Electrode Characteristics and Lithiation Mechanism of FePc/GN Composites
}

\author{
Haoqi Yang ${ }^{1}$, Pinchao Fan ${ }^{1}$, Shuwu Liu ${ }^{1}$, Junhua Wei ${ }^{2,3 *}$, Siping Tan ${ }^{2,3}$, \\ Qingjie Wang ${ }^{2,3}$ and Haoqing Hou ${ }^{1 *}$ \\ ${ }^{1}$ Department of Chemistry and Chemical Engineering, Jiangxi Normal University, Nanchang, 330022, \\ China. \\ ${ }^{2}$ Guizhou Meiling Battery Co., Ltd, Zunyi, 563003, China \\ ${ }^{3}$ State Key Laboratory of Advanced Chemical Power Sources \\ *E-mail: haoqing@jxnu.edu.cn (H. Hou); junhuawei09@163.com (J. Wei)
}

doi: $10.20964 / 2018.03 .45$

Received: 15 November 2017 / Accepted: 10 January 2018 / Published: 5 February 2018

Iron-phthalocyanine $(\mathrm{FePc})$, a metal-organic compound containing a large $\pi$-conjugated and planar multi-ring aromatic structure, can be employed as an organic anode material for lithium-ion batteries. To overcome the poor electronic conductivity of FePc, a good electrically conductive graphene nanosheet carbon skeleton is integrated by a one-step simple mechanical mixing strategy. In addition, the weight ratio of FePc and graphene nanosheets (GNs) is systematically optimized. Electrochemical tests show that the as-prepared 1/2.25-FePc/GN composite exhibits a high reversible capacity of 872 $\mathrm{mAh} \mathrm{g}^{-1}$, the specific capacity based on iron-phthalocyanine is up to $1614 \mathrm{mAh} \mathrm{g}^{-1}$. The excellent electrochemical performance of $\mathrm{FePc} / \mathrm{GN}$ is mainly attributed to the synergistic effect of FePc (large $\pi$ conjugated structure, rich in $\mathrm{N}$ atoms and aromatic rings) and graphene (flexibility and good electrical conductivity).

Keywords: Iron-phthalocyanine; Energy storage; Organic electrode material; Lithium-ion batteries

\section{FULL TEXT}

(C) 2018 The Authors. Published by ESG (www.electrochemsci.org). This article is an open access article distributed under the terms and conditions of the Creative Commons Attribution license (http://creativecommons.org/licenses/by/4.0/). 